activity states [remission (SLEDAI-2K=0) and lupus low disease activity state (LLDAS)], accrual of irreversible damage (SLICC damage index, SDI), number and severity of flares, and side-effects. Analyses were performed at quarterly intervals and only patients with at least 3 months of follow-up were included in the study. Results: A total of 56 patients were included [53 women (94.6\%), mean (SD) age 46.3 (12.7) years]. Evidence of serologic activity (low C3/C4 and/or high anti-ds DNA) was evident in 30 patients $(53.5 \%)$. Most frequent manifestations were arthritis $(82.1 \%)$, inflammatory rash $(73.2 \%)$, active hair loss $(57.1 \%)$, mucosal ulcers $(26.8 \%)$ and leukopenia $(10.7 \%)$.

Median (range) duration of follow-up was $9.1(2.9$ - 34.6) months. We observed a significant decrease in the SLEDAI-2K, physician global assessment (PGA) and daily prednisone dose over time, starting as early as 3 months after belimumab initiation (Table 1). This effect was significantly more pronounced in patients who were serologically active (SA) at baseline, even after exclusion of the serologic component of the SLEDAI [median (range) clinical SLEDAI-2K for SA patients: 7 $(1-24)$ at baseline vs. $2(0-16)$ at 6 months and $2(0-16)$ at 12 months, $p<0.0001$ and $p=0.013$, respectively; for serologically inactive patients: $6(2-23)$ at baseline vs. $6(0-14)$ at 6 months and $5(0-18)$ at 12 months, $p=0.017$ and $p=0.024$, respectively]. For patients with $\geq 12$ months of follow-up $(n=20)$, belimumab treatment resulted in a significant decrease in flare rate [median (range) total number of flares for the 12 months before and after belimumab treatment, 3 $(0-7)$ and $0(0-2)$, respectively, $p<0.0001) .10$ patients $(17.8 \%)$ discontinued belimumab due to inefficacy after a median (range) $7.1(5.5$ - 20.4) months of therapy and 5 patients discontinued due to planned pregnancy. There were no drug discontinuations due to side-effects.

\begin{tabular}{|c|c|c|c|c|c|c|c|}
\hline & $\begin{array}{c}\begin{array}{c}\text { Baseline } \\
\text { (reference) } \\
n=56\end{array} \\
\end{array}$ & $\begin{array}{c}3 \text { months } \\
n=56\end{array}$ & $\begin{array}{c}6 \text { months } \\
n=47\end{array}$ & $\begin{array}{c}9 \text { months } \\
n=26\end{array}$ & $\begin{array}{c}12 \text { months } \\
n=22\end{array}$ & $\begin{array}{c}18 \text { months } \\
n=10\end{array}$ & p value \\
\hline \multirow[t]{2}{*}{$\begin{array}{l}\text { SLEDAl, } \\
\text { median } \\
\text { (range) }\end{array}$} & $8(2-28)$ & $6(0-24)^{\circ}$ & $4(0-20)^{*}$ & $4(0 .-18)^{\circ}$ & $4(0-18)^{\circ}$ & $3(0-14))^{*}$ & $\begin{array}{l}\cdot p<0.001 \\
\cdot * p=0.01\end{array}$ \\
\hline & $\begin{array}{c}\text { Baseline } \\
\text { (reference) }\end{array}$ & 3 months & 6 months & 9 months & 12 months & 18 months & p value \\
\hline \multirow[t]{2}{*}{$\begin{array}{l}\text { PGA median } \\
\text { (range) }\end{array}$} & $1.9(1-3)$ & $1.5(0.3-3)^{*}$ & $1.5(0.5-3)^{-}$ & $1.5(0-2.2)^{*}$ & $1.15(0-3)^{*}$ & $1(0-2) \cdots$ & 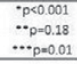 \\
\hline & $\begin{array}{c}\text { Baseline } \\
\text { (reference) }\end{array}$ & 3 months & 6 months & 9 months & 12 months & 18 months & p value \\
\hline $\begin{array}{l}\text { Pz dose, } \\
\text { median } \\
\text { (range) }\end{array}$ & $7.5(0-40)$ & $7.5(0-30)^{*}$ & $5(0-25)^{\circ}$ & $5(0-10)^{\circ}$ & $5(0-30) \cdots$ & $4.3(0-7.5) \cdots$ & $\begin{array}{c}c p<0.001 \\
\cdots p=0.001 \\
\cdots p p=0.021\end{array}$ \\
\hline $\begin{array}{c}\text { Low disease } \\
\text { activity states, } \\
n(\%)\end{array}$ & Baseline & 3 months & 6 months & 9 months & 12 months & 18 months & \\
\hline ULAS & $0(0)$ & $10(17.9)$ & $15(31.9)$ & $10(34.5)$ & $5(21.7)$ & $4(40)$ & \\
\hline Remission & $0(0)$ & $3(5.4)$ & $4(7.1)$ & $3(5.4)$ & $4(7.1)$ & $2(3.6)$ & \\
\hline
\end{tabular}

Conclusions: In real-life clinical settings, belimumab is efficacious in controlling disease activity of SLE and permitting tapering of glucocorticoid dose. Similar to data from RCTs, this effect seems to be more pronounced in serologically active patients.

Disclosure of Interest: None declared

DOI: 10.1136/annrheumdis-2017-eular.4825

\section{AB0443 INFUSION REACTIONS TO RITUXIMAB IN SYSTEMIC LUPUS ERYTHEMATOSUS: A RETROSPECTIVE ANALYSIS}

A. Hennessey ${ }^{1,2}$, J. Lukawska $^{3}$, G. Cambridge ${ }^{1}$, D. Isenberg ${ }^{1,2}$, M. Leandro ${ }^{1,2}$ ${ }^{1}$ Centre for Rheumatology and Bloomsbury Rheumatology Unit, University College London; ${ }^{2}$ Division of Rheumatology, Department of Medicine; ${ }^{3}$ Allergy Medicine, University College London Hospitals, London, United Kingdom

Background: B-cell depletion with Rituximab (RTX) has been used since since 2000 in the treatment of Systemic Lupus Erythematosus (SLE). An issue with the use of RTX is the attrition rate due reactions during of following infusions. This can prevent re-treatment with RTX in patients with a good initial response to RTX and in whom other treatments had failed, this is especially important in SLE patients with limited biologic options.

Objectives: To identify the rates and patient characteristics of infusion reactions to RTX in patients with SLE.

Methods: A retrospective analysis of the SLE patient cohort receiving RTX at University College London Hospitals via examination of patient records was used to determine if there was a clinically significant reaction (from clinic letters or discharge summary) for each RTX infusion. One cycle of RTX refers to 2 infusions given 2 weeks apart. A descriptive analysis of the reaction was recorded as was the decision making surrounding the infusions.

Results: Records from 151 RTX-treated patients were reviewed with 13 excluded due to missing data. 138 remaining patients (130 females and 8 males, mean age (1st infusion) $=33$ years; range: $16-73$ ) received a total of 478 individual RTX infusions (between 1-9 cycles). Prior to 2007, standard of care was to receive Cyclophosphamide (CYC) with each cycle. The total rate of infusion reactions was $5.85 \%$ (23 patients had 28 reactions). Of these $4(50 \%)$ were males, 19 females ( $14.6 \% ; p=0.009$, Chi square). Average number of cycles in those without, compared to with a reaction was 1.61 vs 1.64 . With 1 st dose, 7 patients $(25 \%)$ had reactions, 19 with 2 nd $(67.9 \%) .3$ patients were retreated $(1$ twice); $2 / 3$ had further reactions and the 3rd two further cycles without issues. Most were not retreated. Reactions ranged from mild to severe (Table 1). A total of 24 RTX reactions were categorized into: Immediate- unlikely immune mediated 4; likely cytokine release 7; IgE mediated 5; and bone pain reactions 2 . Delayedearly (24-48hours) 1 ; and late (>48hours) 5 ; by a Clinical Allergist. 4 reactions were excluded from this analysis; 1 death as likely CYC induced (but occurred within 24 hours of RTX) and 3 due to lack of data.

Table 1. Severity of Infusion Reactions

\begin{tabular}{lccc}
\hline Severity of reaction Number of patients \% of total infusion reactions & Retreated? \\
\hline Death & 1 & $3.6 \%$ & $\mathrm{~N}$ \\
Severe & 3 & $10.7 \%$ & $\mathrm{Y}-1$ (had further reaction) \\
Moderate & 7 & $25.0 \%$ & $\mathrm{Y}-1$ (2 further cycles) \\
Mild & 8 & $28.6 \%$ & $\mathrm{Y}-1$ (2 further cycles) \\
Delayed & 5 & $17.9 \%$ & $\mathrm{Y}-1$ (1 further cycle) \\
Unclassified & 4 & $14.3 \%$ & $\mathrm{~N}$ \\
\hline
\end{tabular}

Mild (infusion resumed/completed), Moderate (had to cease infusion reaction), Severe (hospital admission), Delayed/serum sickness.

Conclusions: The number of previous cycles was similar in patients who reacted versus those who did not. Patients were most likely to experience a clinically significant reaction with the second infusion. Males had higher incidence of reactions. Most (19\%) were immediate and the majority $(79 \%)$ of immediate and delayed reactions occurred during 1 st (10) and 2nd (9) cycles. The total rate of infusion reactions in this cohort was lower than previously reported however this is likely contributed to by the limitations of a retrospective review. However $64 \%$ of reactions $(11 / 17)$ in this cohort were significant, necessitating cessation of infusion or hospital admission.

Disclosure of Interest: A. Hennessey: None declared, J. Lukawska: None declared, G. Cambridge: None declared, D. Isenberg: None declared, M. Leandro Consultant for: Roche UK and Roche Basel and Genentech DOI: 10.1136/annrheumdis-2017-eular.5875

\section{AB0444 EFFECT OF RITUXIMAB ON A SALIVARY GLAND ULTRASOUND SCORE IN PRIMARY SJÖGREN'S SYNDROME: RESULTS OF THE TRACTISS MULTICENTRE RANDOMISED TRIAL SUB-STUDY}

B.A. Fisher ${ }^{1}$, C.C. Everett ${ }^{2}$, J. Rout ${ }^{3}$, J.L. O'Dywer ${ }^{4}$, P. Emery ${ }^{5}$, C. Pitzalis ${ }^{6}$ W.-F. $\mathrm{Ng}^{7}$, A. Carr ${ }^{8}$, C.T. Pease ${ }^{5}$, E.J. Price ${ }^{9}$, N. Sutcliffe ${ }^{10}$, J. Makdissi ${ }^{10}$, N.S. Gendi ${ }^{11}$, F.C. Hall ${ }^{12}$, S.P. Ruddock ${ }^{2}$, C. Fernandez ${ }^{2}$, C.T. Hulme ${ }^{4}$, K.A. Davies ${ }^{13}$, C.J. Edwards ${ }^{14}$, P.C. Lanyon ${ }^{15}$, R.J. Moots ${ }^{16}$, E. Roussou ${ }^{17}$, L.D. Sharples ${ }^{18}$, M. Bombardieri ${ }^{6}$, S.J. Bowman ${ }^{1} .{ }^{1}$ Rheumatology, University of Birmingham, Birmingham; ${ }^{2}$ Leeds Institute for Clinical Trials Research, Leeds; ${ }^{3}$ Dental Hospital, Birmingham; ${ }^{4}$ Health Economics; ${ }^{5}$ LMBRU, University of Leeds, Leeds; ${ }^{6}$ Barts and the London School of Medicine, London; ${ }^{7}$ Musculoskeletal Research Group, University of Newcastle; ${ }^{8}$ Newcastle University, Newcastle; ${ }^{9}$ Great Western Hospital, Swindon; ${ }^{10}$ Royal London Hospital, London; ${ }^{11}$ Basildon and Thurrock University Hospital, Basildon; ${ }^{12}$ University of Cambridge, Cambridge; ${ }^{13}$ Brighton and Sussex Medical School, Brighton; ${ }^{14}$ University Hospital Southampton, Southampton; ${ }^{15}$ University of Nottingham, Nottingham; ${ }^{16}$ University of Liverpool, Liverpool; ${ }^{17}$ BHRUT, Goodmayes; ${ }^{18}$ London School of Hygiene and Tropical Medicine, London, United Kingdom

Background: B lymphocytes are important in the pathogenesis of primary Sjögren's syndrome (PSS), but two phase III trials (TEARS and TRACTISS) of the $B$ cell depleting agent rituximab (RTX) failed to show an effect on their primary endpoints in PSS. Whilst RTX may lack efficacy in a non-stratified PSS population, other possible explanations for these negative results include the choice and timing of primary outcome. In a small single-site salivary gland ultrasound (SGUS) substudy in TEARS, more subjects in the RTX arm demonstrated improvement in parotid gland echostructure. Importantly, SGUS is an operator-dependent technique.

Objectives: To compare the effects of RTX versus placebo on SGUS in PSS, in a multicentre, multiobserver substudy of TRACTISS.

Methods: Subjects consenting to SGUS were randomised to $1000 \mathrm{mg} \mathrm{RTX}$ or placebo given at weeks 0,2, 24 and 26, and scanned at baseline and weeks 16 and 48. Sonographers completed a $0-11$ total ultrasound score (TUS) comprising domains of echogenicity, homogeneity, glandular definition, glands involved, and size of hypoechoic foci. Baseline-adjusted values of TUS were analysed over time, modelling change from baseline at each time point. For each TUS domain we fitted a repeated measures logistic regression model to model the odds of a response in the RTX arm (defined as a 1 point improvement) as a function of the baseline score, age category, disease duration and time point.

Results: 66 patients (49.6\% of the total study population) consented to SGUS, and $52(39.1 \% ; n=26$ RTX and $n=26$ placebo) completed the baseline and at least one follow-up visit. Estimated baseline-adjusted TUS at week 16 was 6.2 (95\% Cl 5.4-7.0) for placebo and $5.0(95 \% \mathrm{Cl} 4.4-5.6)$ for RTX, and at week 48 , $6.1(95 \% \mathrm{Cl} 5.5-6.6)$ and $4.8(95 \% \mathrm{Cl} 4.2-5.4)$ respectively. Estimated between group differences (RTX-placebo) in baseline adjusted TUS were $-1.2(95 \% \mathrm{Cl}$ -2.1 to $-0.3 ; p=0.0099)$ and $-1.2(95 \% \mathrm{Cl}-2.0$ to $-0.5 ; \mathrm{p}=0.0023)$ at weeks 16 and 48 . Glandular definition was the only domain to show statistically significant improvement with an OR of $6.8(95 \% \mathrm{Cl} 1.1-43.0 ; \mathrm{p}=0.043)$ at week 16 and 10.3 $(95 \% \mathrm{Cl} 1.0-105.9 ; \mathrm{p}=0.050)$ at week 48 . Improvement of $>1$ point in TUS was associated with improvement in oral dryness VAS at week 16 (diff $=15.9 ; \mathrm{Cl} 1.5$ to 30.3; $p=0.030$ ) but not week 48 in the RTX arm. 
Conclusions: TUS differed between study arms, favouring RTX. This encourages further research into SGUS as an imaging biomarker in PSS clinical trials. Acknowledgements: Funded by Arthritis Research UK. Roche provided RTX. Disclosure of Interest: B. Fisher Paid instructor for: Novartis, Roche, Virtualscopics, C. Everett: None declared, J. Rout: None declared, J. O'Dywer: None declared, P. Emery: None declared, C. Pitzalis: None declared, W.-F. Ng Consultant for: Pfizer, UCB, Medlmmune, Takeda and Sanofi, A. Carr: None declared, C. Pease: None declared, E. Price: None declared, N. Sutcliffe: None declared, J. Makdissi: None declared, N. Gendi: None declared, F. Hall: None declared, S. Ruddock: None declared, C. Fernandez: None declared, C. Hulme: None declared, K. Davies: None declared, C. Edwards: None declared, P. Lanyon: None declared, R. Moots: None declared, E. Roussou: None declared, L. Sharples: None declared, M. Bombardieri Consultant for: GSK, Amgen/Medlmmune and UCB, S. Bowman Consultant for: Cellgene, Glenmark, GSK, Eli Lilly, Novartis, Roche, Takeda, UCB

DOI: 10.1136/annrheumdis-2017-eular.3138

\section{AB0445 HYDROXYCHLOROQUINE'S IMPACT IN RENAL BIOPSY AND OUTCOMES OF LUPUS NEPHRITIS}

D. Navarro, A.C. Ferreira, H. Viana, F. Carvalho, F. Nolasco. Nephrology Department, Hospital Curry Cabral, Lisboa, Portugal

Background: Given its immunomodulatory effects, hydroxychloroquine use is recommended in systemic lupus erythematosus (SLE). It is associated with a lower rate of appearance and of relapse of lupus nephritis (LN). LN is classically classified using ISN/RPS classification, but others indexes, such as the ones described by Austin and Hill, allow for the quantification of SLE activity in the kidney tissue.

Objectives: To analyze the association between the use of hydroxychloroquine and the activity of LN in the kidney biopsy.

Methods: Retrospective single center study of consecutive SLE and biopsy proven LN patients, diagnosed from 2010 to 2016 . We evaluated the following outcomes: clinical remission, renal function and proteinuria at end of followup $(\mathrm{g} / 24 \mathrm{~h})$. Complete remission was defined as a reduction of proteinuria to $<0,5 \mathrm{~g} / 24 \mathrm{~h}$, inactive urinary sediment and serum creatinine $<115 \%$ of baseline; partial remission same parameters, except proteinuria $<1 \mathrm{~g} / 24 \mathrm{~h}$ if initial value $<3 \mathrm{~h} / 24 \mathrm{~h}$, or reduction to $<3 \mathrm{~g} / 24 \mathrm{~h}$ if initial value $>3 \mathrm{~g} / 24 \mathrm{~h}$. Kidney biopsies were evaluated by the INS/RPS LN classification and the morphological indexes described by Austin and Hill, obtained after histomorphological review of renal biopsies. The studied predictor was the use of hydroxychloroquine. Statistical analysis was performed with STATA software, using one-way ANOVA, Qui2 and Pearson/Sperman test were appropriate.

Results: During 6 years, there were 46 biopsy-proven LN cases, $84,8 \%(n=39)$ woman, median 35 years old $(27-42,5)$ and $57,6 \% \quad(n=19)$ caucasian. 39 patients were already known to have SLE, $7,44(1,13-12,3)$ years previously. Of those 39 patients, $46 \%$ were under hydroxychloroquine and $77 \%$ under other immunosuppression.

The median follow-up was $31,9(13,2-45,6)$ months. Based on biopsy findings, 35 patients were started on immunosuppression - induction in $50 \%$ of cases with MMF and in $50 \%$ with cyclophosphamide; maintenance in $81 \%$ with MMF, the rest with azathioprine. Complete remission was achieved in $58 \%$ of patients, $27 \%$ achieving partial remission. We observed $4 \mathrm{LN}$ relapses. At the end of FUP, we saw a $96 \%(n=44)$ patient survival, with a median serum creatinine of $0,8 \mathrm{mg} / \mathrm{dl}$ $(0,7-0,99)$, eGFR $99,8 \mathrm{ml} / \mathrm{min}(71,2-116,8)$ and proteinuria of $0,6 \mathrm{~g} / 24 \mathrm{~h}(0,2-1,6)$. From those 46 patients, 30 were under immunosuppressive therapy at time of LN presentation, and $60 \%(n=18)$ were also under hydroxychloroquine. Table 1 summarizes the clinical findings:

With the use of hydroxychloroquine, we observed a lower histomorphological activity, as represented by a lower Hill biopsy index, and tendency towards lower Activity index. We also saw a tendency towards lower proteinuria.

Conclusions: Our data reinforces the recommendations of using hydroxychloroquine for its adjuvant role in SLE patients, as we saw a lower histomorphological activity in kidney biopsy, and a trend towards lower proteinuria.

Disclosure of Interest: None declared

DOI: 10.1136/annrheumdis-2017-eular.5546

\section{AB0446 ADDITIVE INHIBITION OF INTERFERONS, B AND T CELL ACTIVATION AND TFH-RELATED CYTOKINE CXCL13 BY LEFLUNOMIDE AND HYDROXYCHLOROQUINE SUPPORTS RATIONALE FOR COMBINATION THERAPY IN PSS PATIENTS}

E.H. van der Heijden ${ }^{1,2}$, S.A. Hartgring ${ }^{1,2}$, A.A. Kruize ${ }^{2}$, T.R. Radstake ${ }^{1,2}$, J.A. van Roon ${ }^{1,2}$. ${ }^{1}$ Laboratory of Translational Immunology; ${ }^{2}$ Dept. of Rheumatology \& Clinical Immunology, UMC Utrecht, Utrecht, Netherlands
Background: T and B cell-driven immunity is critically involved in immunopathology of pSS. Recently we demonstrated synergistic T and B-cell activation upon T cell triggering and TLR7/9-driven B cell activation in pSS patients, accompanied by synergistic induction of immunoglobulins and IFN- $\gamma$ - and IL-17-producing T cells ${ }^{1}$. In addition, TLR7/9-expressing activated pDCs associated with increased type I IFNs and IFN-inducible genes are increased pSS patients. Several studies have shown that the DMARDs leflunomide and hydroxycholoroquine inhibit immune activation in pSS but only show moderate efficacy. However, LEF and HCQ target different pathways with overlapping, but also potentially additive mechanisms, where LEF primarily targets $\mathrm{T}$ and $\mathrm{B}$ cells and HCQ TLR7/9-driven B cell and pDC activation.

Objectives: To assess the additive effects of LEF and HCQ on CD4 T- and B-cell activation and production of interferons IFN- $\alpha$ and IFN- $\gamma$, Tfh-related cytokine CXCL13, as well as IgG and IgM in vitro employing SEB/TLR9-triggered PBMC. Methods: PBMCs of healthy individuals $(n=9)$ and of pSS patients $(n=8)$ were cultured with antigen (SEB), TLR9 and their combination, in presence or absence of LEF, HCQ and their combination in clinical relevant concentrations. Proliferation of $T$ and $B$ cells and release of IFN- $\alpha, \operatorname{IFN}-\gamma, C X C L 13, \lg G$ and IgM were measured.

Results: In line with robust $\mathrm{T}$ and $\mathrm{B}$ cell activation, IFN- $\gamma, \mathrm{IFN} \alpha, \mathrm{CXCL} 13, \operatorname{IgG}$ and IgM production was achieved by a combination of SEB and TLR9 (all at least $\mathrm{p}<0.001$ ). LEF dose dependently inhibited $\mathrm{B}$ and $\mathrm{T}$ cell proliferation, Interferon, CXCL13 and immunoglobulin production. HCQ dose dependently inhibited B cell proliferation, IFN- $\alpha, \mathrm{CXCL13}$, and immunoglobulin production. T cell proliferation and IFN- $\gamma$ production were inhibited by $\mathrm{HCQ}$ only at higher concentrations. At several suboptimal concentrations LEF and HCQ additively inhibited T cell proliferation both in healthy individuals and in pSS patients. (Figure 1). Significant additive effects were seen for all outcome measures except IFN- $\alpha$. Since IFNa was already robustly inhibited by $\mathrm{HCQ}$ alone (eg.for pSS $90 \%$ at $3.3 \mu \mathrm{M}, \mathrm{p}<0.001$ ), only trends towards additive effects were observed.

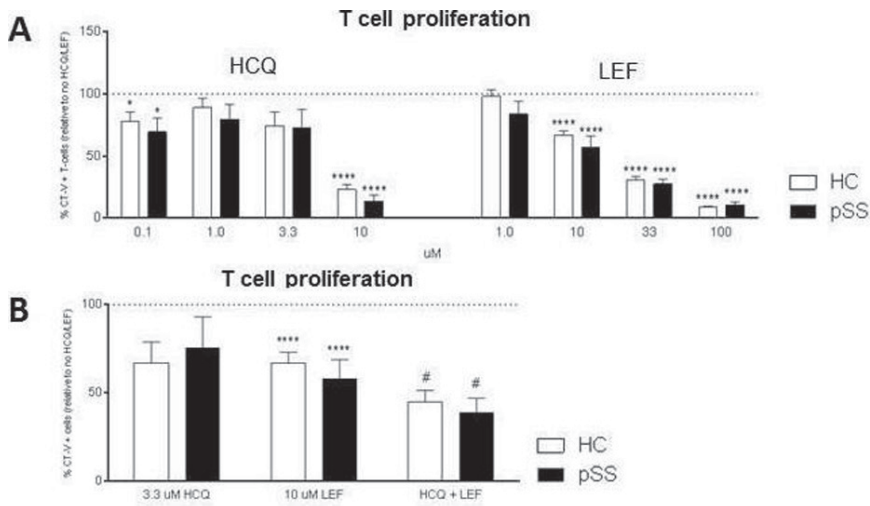

Figure 1. HCQ and LEF additively inhibit T cell activation. T cell proliferation is dose dependently inhibited by LEF and by HCQ at 0.1 and $10 \mu \mathrm{M}$ (A). Significant additive inhibition of $T$ cell proliferation is achieved by combination of suboptimal concentrations of LEF and HCQ both in $\mathrm{HC}$ and pSS patients (B). *and **** indicates statistical significance of $p<0.05$ and $p<0.0001$ resp. vs control, \# indicates statistical significance of $p<0.05$ of the combination vs each of the single drugs.

Conclusions: LEF and $\mathrm{HCQ}$ robustly inhibited proliferation of $\mathrm{T}$ and $\mathrm{B}$ cells, cytokine production and immunoglobulin production with clear additive efficacy in both healthy individuals as in pSS patients. These data support the potential surplus value of combination therapy with LEF and HCQ for patients with pSS. References:

[1] Bikker et al. Interleukin-7 and Toll-Like Receptor 7 induce synergistic B cell and T cell activation. PLoS ONE 9(4): e94756.

Disclosure of Interest: None declared

DOI: 10.1136/annrheumdis-2017-eular.5022

\section{AB0447 ANTIMALARIALS IMPROVE SURVIVAL OF SYSTEMIC LUPUS ERYTHEMATOSUS ON CHOLESTEROL: RESULTS OF A FIFTEEN-YEAR CHINESE MULTICENTER RETROSPECTIVE STUDY IN JIANGSU PROVINCE}

F. Wang ${ }^{1}$, W. Zhang ${ }^{1}$, S. Wang ${ }^{1}$, W. Pan ${ }^{2}$, L. Liu ${ }^{3}$, M. Wu ${ }^{4}$, X. Ding ${ }^{5}$, H. Wei ${ }^{6}$, Y. Zou ${ }^{7}$, X. Feng ${ }^{1}$, L. Sun ${ }^{1} .{ }^{1}$ Department of Rheumatology and Immunology, the Affiliated Drum Tower Hospital of Nanjing University Medical School, Nanjing; 22Department of Rheumatology, Huaian First People's Hospital, Huaian ${ }^{3}$ Department of Rheumatology, Xuzhou Central Hospital, Xuzhou;

Abstract AB0445 - Table 1

\begin{tabular}{|c|c|c|c|c|c|c|c|c|c|c|}
\hline Hydroxychloroquine use & Class II & Class III & Class IV & Class V & $\begin{array}{l}\text { Hill Biopsy } \\
\text { Index }\end{array}$ & $\begin{array}{l}\text { Activity } \\
\text { Index }\end{array}$ & $\begin{array}{l}\text { Chronicity } \\
\text { Index }\end{array}$ & $\begin{array}{l}\text { End of FUP eGFR } \\
\qquad(\mathrm{ml} / \mathrm{min})\end{array}$ & $\begin{array}{l}\text { End of FUP serum } \\
\text { creatinine }(\mathrm{mg} / \mathrm{dl})\end{array}$ & $\begin{array}{l}\text { End of FUP proteinuria } \\
(\mathrm{g} / 24 \mathrm{~h})\end{array}$ \\
\hline Yes $(n=18)$ & $39 \%$ & $28 \%$ & $28 \%$ & $22 \%$ & $0,86(0,2-1,8)$ & $1(0-4,25)$ & $0,75(0-3,25)$ & $99,8(81,9-112,1)$ & $0,74(0,7-0,8)$ & $0,3(0,1-0,6)$ \\
\hline No $(n=12)$ & $8 \%$ & $17 \%$ & $58 \%$ & $33 \%$ & $1,52(0,98-2,01)$ & $7,25(1,38-9)$ & $2,25(0,13-5,25)$ & $98,6(56,4-120,3)$ & $0,78(0,7-1,3)$ & $0,75(0,15-2,6)$ \\
\hline$p$-value & 0,09 & NS & NS & NS & 0,03 & 0,07 & NS & NS & NS & 0,09 \\
\hline
\end{tabular}

